\title{
Perancangan Geometrik dan Perkerasan Jalan Tol Kertosono-Kediri (Kertosono STA 0+000 sampai Kediri STA 21+300)
}

\author{
Heni Prasetyo, Hera Widyastuti, dan Anak Agung Gde Kartika \\ Departemen Teknik Sipil, Institut Teknologi Sepuluh Nopember (ITS) \\ e-mail:kartika@ce.its.ac.id
}

\begin{abstract}
Abstrak-Dengan terus meningkatnya perekonomian di wilayah Jawa Timur terutama di wilayah Kertosono dan Kediri, maka mobilitas atau pergerakan barang dan jasa antara kedua wilayah ini pun semakin meningkat. Oleh karena itu diperlukan adanya jalur alternatif yang menghubungkan Kertosono-Kediri dan dipilih jalan tol sebagai jalur alternatif. Pembangunan jalan tol merupakan solusi karena dapat mengalihkan kepadatan lalu lintas yang terjadi di Simpang Tiga Mengkreng, Kertosono sehingga dapat menimbulkan kelancaran arus lalu lintas dan efisiensi. Trase yang digunakan pada Jalan Tol KertosonoKediri mengacu pada studi terdahulu dengan judul "Perencanaan Trase Pembangunan Jalan Tol Kertosono-Kediri Ditinjau dari Kelayakan Ekonomi dan Finansial" oleh Dea Adlina Tiara Wibowo yang dibimbing oleh Ir. Hera Widyastuti, MT, Ph.D. Dari hasil perancangan jalan tol ini didapatkan jumlah lengkung sebanyak 11 dan lengkung vertikal sebanyak 15. Tebal lapisan perkerasan kaku didapatkan $285 \mathrm{~mm}$ pada badan jalan dan $265 \mathrm{~mm}$ pada bahu jalan dengan lapisan tambahan pada keduanya yaitu lapisan beton kurus (LMC) 100 mm, lapisan drainase 150 mm dan lapisan stabilisasi semen 300 mm.Total anggaran biaya material untuk pembangunan Jalan Tol ini sebesar Rp 428.076.783.131.
\end{abstract}

Kata Kunci-Jalan Tol, Perancangan Geometrik, Perkerasan Jalan.

\section{PENDAHULUAN}

$\mathbf{J}^{\prime}$ ALAN adalah prasarana transportasi darat yang meliputi $\mathcal{J}$ segala bagian jalan, termasuk bangunan pelengkap dan perlengkapannya yang diperuntukkan bagi lalu lintas [1]. Jalan raya sebagai bagian sistem transportasi nasional mempunyai peranan penting terutama dalam mendukung bidang ekonomi agar tercapai keseimbangan dan pemerataan pembangunan antar daerah. Seiring dengan perkembangan ekonomi, kesejahteraan masyarakat pun meningkat sehingga intesitas penggunanan jalan juga meningkat.

Jawa Timur yang merupakan salah satu provinsi terbesar di Indonesia memiliki peran penting dalam pembangunan nasional, dengan jumlah penduduk mencapai 39.292.972 jiwa dan luas wilayah $47.992 \mathrm{~km}^{2}$ [2]. Rata-rata laju pertumbuhan penduduk Provinsi Jawa Timur pada tahun 2016 hingga tahun 2017 adalah 0,56\% per tahun. Dengan bertambahnya jumlah penduduk, menjadikan Provinsi Jawa Timur semakin padat, sehingga mobilitas atau pergerakan barang dan jasa antara kedua wilayah ini pun semakin meningkat. Hal itu tentu menuntut akan adanya perkembangan di segi fasilitas transportasi.

Di sisi lain, jalan Kertosono-Kediri merupakan jalan provinsi yang seringkali dilewati oleh bus dan kendaraan berat. Belum adanya jalur alternatif yang menghubungkan antara Kertosono dengan kota Kediri menyebabkan gangguan pada kelancaran arus lalu lintas, sehingga tidak jarang

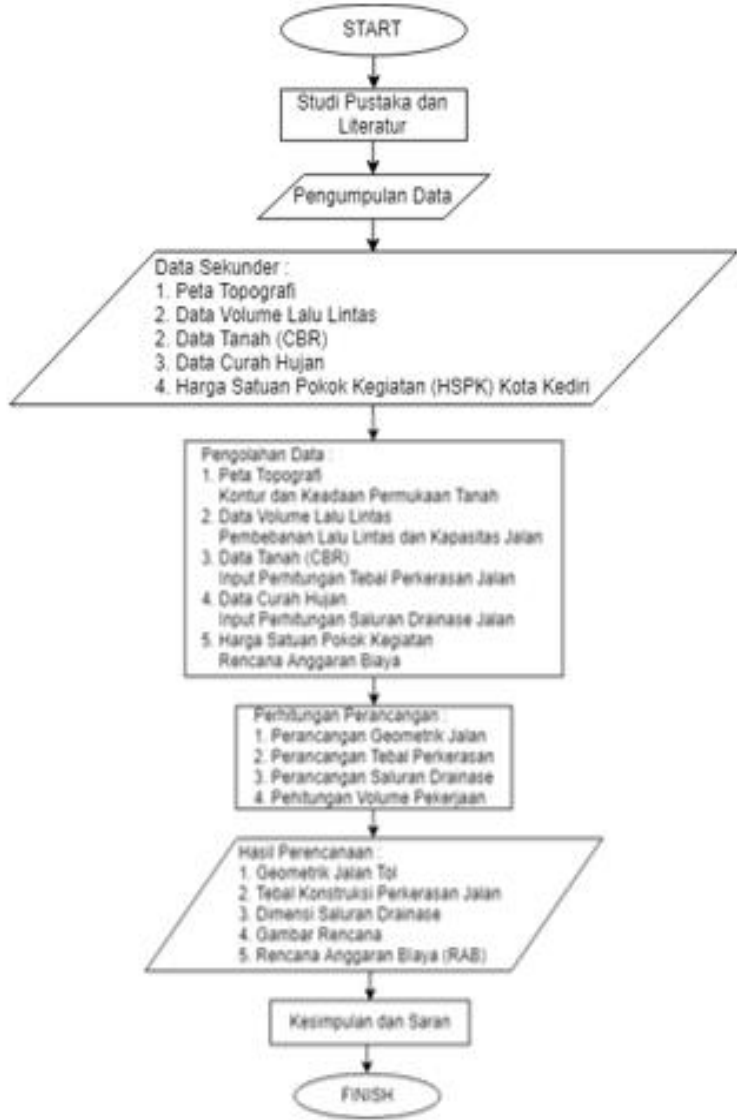

Gambar 1. Bagan Alir Penyusunan Perancangan.

berbagai jenis kendaraan melambat dan menumpuk di jalur ini. Kemacetan sering terjadi pada pertigaan simpang tiga Mengkreng Kertosono yang merupakan titik temu dari Kabupaten Kediri, Kabupaten Nganjuk, Kabupaten Jombang, dan persimpangan sebidang rel kereta api. Kemacetan juga disebabkan oleh adanya aktivitas perbaikan jalan oleh dinas terkait. Hal ini dikarenakan tingginya jumlah kendaraan berat yang melalui jalur ini dan tidak jarang kendaraan berat tersebut mengangkut muatan yang melebihi muatan maksimum yang boleh dibawa oleh kendaraan tersebut. Kendaraan berat dengan muatan melebihi kapasaitas maksimum inilah yang dapat memperpendek umur pelayanan perkerasan jalan pada jalur Kertosono-Kediri.

Program pembangunan jalan tol antar kota di Pulau Jawa yang telah tercantum pada Lampiran III Peraturan Pemerintah Nomor 26 Tahun 2008 tentang Rencana Tata Ruang Wilayah Nasional (RTRWN) terdiri dari 38 ruas, satu diantaranya adalah ruas Ngawi-Kertosono. Jalan Tol Ruas NgawiKertosono, terdiri dari 4 (empat) seksi, yaitu : NgawiMadiun, Madiun-Caruban, Caruban-Nganjuk dan Nganjuk- 
Tabel 1.

Parameter Lengkung Horizontal

\begin{tabular}{|c|c|c|c|c|c|c|}
\hline Tikungan & $\begin{array}{l}\text { Rmin } \\
(\mathrm{m})\end{array}$ & $\begin{array}{l}\text { Ro } \\
\text { (m) }\end{array}$ & $\begin{array}{l}\text { Ls } \\
(\mathrm{m})\end{array}$ & $\mathrm{e}$ & $\begin{array}{l}\mathrm{Lc} \\
(\mathrm{m})\end{array}$ & $\begin{array}{l}\text { L total } \\
\text { (m) }\end{array}$ \\
\hline PI -1 & 591 & 750 & 125 & 8,79 & 269 & 519 \\
\hline PI -2 & 591 & 750 & 125 & 8,79 & 453 & 703 \\
\hline PI -3 & 591 & 750 & 125 & 8,79 & 50 & 300 \\
\hline PI -4 & 591 & 750 & 125 & 8,79 & 262 & 511 \\
\hline PI -5 & 591 & 750 & 125 & 8,79 & 105 & 354 \\
\hline PI -6 & 591 & 750 & 125 & 8,79 & 651 & 900 \\
\hline PI -7 & 591 & 750 & 125 & 8,79 & 587 & 836 \\
\hline PI -8 & 591 & 750 & 125 & 8,79 & 868 & 1117 \\
\hline PI -9 & 591 & 750 & 125 & 8,79 & 966 & 1216 \\
\hline PI -10 & 591 & 750 & 125 & 8,79 & 263 & 512 \\
\hline PI -11 & 591 & 750 & 125 & 8,79 & 330 & 580 \\
\hline \multicolumn{7}{|c|}{ Keterangan: } \\
\hline $\mathrm{Rmin}$ & \multicolumn{6}{|c|}{ : Jari-jari tikungan minimum } \\
\hline Ro & \multicolumn{6}{|c|}{ : Jari-jari tikungan rencana } \\
\hline Ls & \multicolumn{6}{|c|}{ : Lengkung peralihan } \\
\hline $\mathrm{e}$ & \multicolumn{6}{|c|}{ : Superlevasi } \\
\hline Lc & \multicolumn{6}{|c|}{ : Panjang busur lingkaran } \\
\hline Ltotal & \multicolumn{6}{|c|}{ : Panjang total tikungan } \\
\hline
\end{tabular}

Tabel 2.

Parameter Lengkung Horizontal

\begin{tabular}{cccccc}
\hline \hline \multirow{2}{*}{ Tikungan } & STA. TS & $\begin{array}{c}\text { STA. } \\
\text { SC }\end{array}$ & $\begin{array}{c}\text { STA. } \\
\text { MID }\end{array}$ & $\begin{array}{c}\text { STA. } \\
\text { CS }\end{array}$ & $\begin{array}{c}\text { STA. } \\
\text { ST }\end{array}$ \\
\hline PI -1 & $0+968$ & $1+092$ & $1+227$ & $1+361$ & $1+486$ \\
PI -2 & $3+183$ & $3+308$ & $3+534$ & $3+761$ & $3+885$ \\
PI -3 & $4+992$ & $5+117$ & $5+142$ & $5+167$ & $5+292$ \\
PI -4 & $8+366$ & $8+491$ & $8+621$ & $8+752$ & $8+877$ \\
PI -5 & $9+953$ & $10+078$ & $10+130$ & $10+183$ & $10+307$ \\
PI -6 & $10+410$ & $10+535$ & $10+861$ & $11+186$ & $11+311$ \\
PI -7 & $14+881$ & $15+006$ & $15+299$ & $15+593$ & $15+717$ \\
PI -8 & $16+613$ & $16+738$ & $17+172$ & $17+606$ & $17+730$ \\
PI -9 & $21+293$ & $21+418$ & $21+901$ & $22+384$ & $22+509$ \\
PI -10 & $23+015$ & $23+140$ & $23+271$ & $23+403$ & $23+528$ \\
PI -11 & $24+348$ & $24+473$ & $24+638$ & $24+804$ & $24+928$ \\
\hline \hline Keterangan: & \multicolumn{7}{c}{} \\
STA. TS & : Sta. titik awal mulai masuk daerah lengkung & \\
STA. SC & : Sta. titik dari spiral ke lingkaran \\
STA. MID & : Sta. titik tengah dari tikungan \\
STA. CS & : Sta. titik dari circle ke spiral \\
STA. ST & : Sta. titik akhir tikungan
\end{tabular}

Kertosono [PP No. 26, 2008]. Dari hasil survei lalu lintas pada tahun 2014, didadapatkan informasi bahwa pada seksi Nganjuk-Caruban terjadi peningkatan jumlah lalu lintas harian, hal ini terjadi karena di Nganjuk terkoneksi dengan jalan arteri menuju Kota Kediri, sebagai pusat kegiatan wilayah (PKW) Kabupaten Kediri eks Ibukota Karisidenan Kediri. Dari hal tersebut, pemerintah dan investor pembangunan Jalan Tol Ngawi-Kertosono melihat potensi besar untuk penambahan seksi Jalan Tol Ngawi-Kertosono, yaitu seksi Kertosono-Kediri, sehingga menjadi ruas NgawiKertosono-Kediri.

Maka, dilatarbelakangi oleh ketiga masalah yang terjadi pada jalur yang menghubungkan kota Kertosono dengan Kota Kediri tersebut, Pemerintah Kota Kediri berencana membangun Jalan Tol Kertosono-Kediri sepanjang 21,30 km sebagai alternatif jalur baru. Pembangunan Jalan Tol Kertosono-Kediri sudah memasuki proses Pra Feasibility Study yang sedang disiapkan oleh Badan Usaha, dan sudah masuk dalam PP No.13 Tahun 2017 [3]. Diharapkan dengan adanya jalan tol yang akan dibangun ini, masyarakat kini memiliki alternatif yang bisa dipilih dalam melakukan perjalanan baik dari Kertosono menuju Kediri atau sebaliknya.

Tujuan dalam perancangan ini yaitu:

1) Merencanakan detail geometrik jalan pada Jalan Tol Kertosono-Kediri.

2) Merencanakan detail struktur tebal perkerasan yang akan
Tabel 3.

Parameter Lengkung Vertikal

\begin{tabular}{ccccc}
\hline \hline $\begin{array}{c}\text { Lengkung } \\
\text { Vertikal }\end{array}$ & $\begin{array}{c}\text { Tipe } \\
\text { Lengkung }\end{array}$ & JPH $(\mathrm{m})$ & L $(\mathrm{m})$ & Ev $(\%)$ \\
\hline PV -1 & Cembung & 250 & 100 & 9,375 \\
PV -2 & Cekung & 250 & 100 & 6,125 \\
PV -3 & Cekung & 250 & 100 & 1,625 \\
PV -4 & Cembung & 250 & 100 & 3,375 \\
PV -5 & Cekung & 250 & 100 & 2,500 \\
PV -6 & Cekung & 250 & 100 & 1,250 \\
PV -7 & Cembung & 250 & 100 & 3,750 \\
PV -8 & Cekung & 250 & 100 & 4,125 \\
PV -9 & Cembung & 250 & 100 & 6,625 \\
PV -10 & Cekung & 250 & 100 & 4,250 \\
PV -11 & Cekung & 250 & 100 & 5,750 \\
PV -12 & Cembung & 250 & 100 & 11,625 \\
PV -13 & Cekung & 250 & 100 & 10,000 \\
PV -14 & Cembung & 250 & 100 & 6,000 \\
PV -15 & Cekung & 250 & 100 & 6,625 \\
\hline \hline
\end{tabular}

Keterangan:

JPH : Jarak pandang henti

L : Panjang lengkung vertikal

Ev : Pergerseran pada bagian titik perpotongan kedua bagian tangen atau pusat perpotongan vertikal

Tabel 4.

Parameter Lengkung Vertikal

\begin{tabular}{lcccccc}
\multicolumn{7}{c}{ Parameter Lengkung } \\
\hline \multirow{2}{*}{ Ver. } & STA. & STA. & STA. & EL. & EL. & EL. \\
& PLV & PPV & PTV & PLV & PPV & PTV \\
\hline PV-1 & $1+750$ & $1+800$ & $1+850$ & $+44,8$ & +45 & $+44,6$ \\
PV-2 & $2+950$ & $3+000$ & $3+050$ & $+40,2$ & +40 & $+40,1$ \\
PV-3 & $4+450$ & $4+500$ & $4+550$ & $+40,2$ & +41 & $+40,8$ \\
PV-4 & $5+950$ & $6+000$ & $6+050$ & $+43,9$ & +44 & $+43,8$ \\
PV-5 & $7+450$ & $7+500$ & $7+550$ & $+44,9$ & +45 & $+44,9$ \\
PV-6 & $8+950$ & $9+000$ & $9+050$ & $+46,9$ & +47 & $+46,8$ \\
PV-7 & $11+950$ & $12+000$ & $12+050$ & $+53,9$ & +54 & $+53,8$ \\
PV-8 & $13+450$ & $13+500$ & $13+550$ & $+53,0$ & +53 & $+52,9$ \\
PV-9 & $14+615$ & $14+665$ & $14+715$ & $+55,9$ & +56 & $+55,7$ \\
PV-10 & $16+450$ & $16+500$ & $16+550$ & $+51,1$ & +51 & $+51,1$ \\
PV-11 & $17+950$ & $18+000$ & $18+050$ & $+51,9$ & +52 & $+51,7$ \\
PV-12 & $19+450$ & $19+500$ & $19+550$ & $+59,7$ & +60 & $+59,9$ \\
PV-13 & $20+950$ & $21+000$ & $21+050$ & $+54,2$ & +54 & +54 \\
PV-14 & $22+715$ & $22+765$ & $22+815$ & $+60,8$ & +61 & $+60,7$ \\
PV-15 & $23+950$ & $24+000$ & $24+050$ & $+60,0$ & +60 & $+59,8$ \\
\hline \hline
\end{tabular}

Keterangan:

STA. PLV : Sta. titik awal mulai masuk lengkung vertikal

STA. PPV : Sta. titik tengah pada lengkung vertikal

STA. PTV : Sta. titik akhir pada lengkung vertikal

EL. PLV : Elevasi titik awal mulai masuk lengkung vertikal

EL. PPV : Elevasi titik tengah pada lengkung vertikal

EL. PTV : Elevasi titik akhir pada lengkung vertikal

digunakan pada Jalan Tol Kertosono-Kediri.

3) Merencanakan saluran drainase pada Jalan Tol Kertosono-Kediri.

4) Mendapatkan rencana anggaran biaya pada Jalan Tol Kertosono-Kediri.

\section{METODOLOGI}

\section{A. Pekerjaan Persiapan}

Sebelum memulai suatu pekerjaan yang pertama kali dilakukan adalah tahap persiapan. Tahap persiapan dilakukan dengan tujuan untuk mempermudah pelaksanaan pekerjaan selanjutnya. Beberapa tahap persiapan antara lain, mencari informasi pada instansi terkait, dan mengurus surat-surat yang diperlukan.

\section{B. Studi Pustaka dan Literatur}

Studi pustaka dan literatur dilakukan dengan membaca sumber bacaan yang mendasari topik dan membantu pengerjaan berupa teori yang berkaitan dengan topik dalam Perancangan ini. 


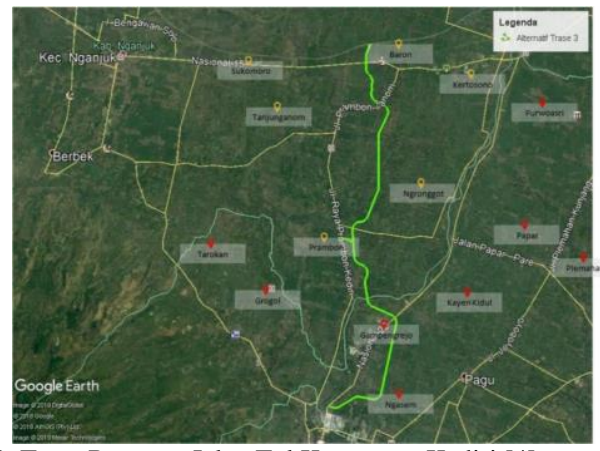

Gambar 2. Trase Rencana Jalan Tol Kertosono-Kediri [4].

Tabel 5.

\begin{tabular}{cccccc}
\multicolumn{7}{c}{ Parameter Lengkung Horizontal } \\
\hline \multirow{2}{*}{ Tikungan } & $\begin{array}{c}\text { R' } \\
(\mathrm{m})\end{array}$ & $\begin{array}{c}\mathrm{M} \\
(\mathrm{m})\end{array}$ & Tikungan & $\begin{array}{c}\mathrm{R}^{\prime} \\
(\mathrm{m})\end{array}$ & $\begin{array}{c}\mathrm{M} \\
(\mathrm{m})\end{array}$ \\
\hline PI -1 & 746,4 & 10,4 & PI -7 & 746,4 & 10,4 \\
PI -2 & 746,4 & 10,4 & PI -8 & 746,4 & 10,4 \\
PI -3 & 746,4 & 3,8 & PI -9 & 746,4 & 10,4 \\
PI -4 & 746,4 & 10,4 & PI -10 & 746,4 & 10,4 \\
PI -5 & 746,4 & 6,9 & PI -11 & 746,4 & 10,4 \\
PI -6 & 746,4 & 10,4 & & & \\
Keterangan: & &
\end{tabular}

Tabel 6 .

Data LHR Eksisting Tahun 2016 [4]

\begin{tabular}{cccc}
\multicolumn{4}{c}{ Data LHR Eksisting Tahun 2016 [4] } \\
\hline \hline $\begin{array}{c}\text { Jenis } \\
\text { Kendaraan }\end{array}$ & $\begin{array}{c}\text { Kertosono- } \\
\text { Papar }\end{array}$ & $\begin{array}{c}\text { Papar- } \\
\text { Kediri }\end{array}$ \\
\hline & & 1412 & 1809 \\
Gol. I & KBM & 590 & 756 \\
& BB & 105 & 135 \\
Gol. II & KBM & 385 & 436 \\
Gol. III & TB & 533 & 463 \\
Gol. IV & TB & 219 & 140 \\
Gol. V & TB & 236 & 508 \\
Gol. VI & SM & 3367 & 4830 \\
JUMLAH & & 6847 & 9077 \\
\hline \hline
\end{tabular}

\section{Tahap Pengumpulan dan Pengolahan Data}

Dalam perancangan Jalan Tol Kertosono-Kediri diperlukan data teknis yang dapat diperoleh dari instansi terkait. Data teknis yang diperlukan sebagai acuan antara lain peta topografi, data LHR, data CBR, data curah hujan, dan HSPK Kota Surabaya. Trase dan data LHR yang digunakan mengacu pada studi terdahulu dengan judul "Perencanaan Trase Pembangunan Jalan Tol Kertosono-Kediri Ditinjau dari Kelayakan Ekonomi dan Finansial” [4].

\section{Diagram Alir (Flow Chart)}

Diagram alir yang berisi urutan pengerjaan Perancangan ini secara lebih jelas dapat dilihat pada Gambar 1.

\section{DATA DAN ANALISIS DATA}

\section{A. Data Lalu Lintas Harian}

Dari data lalu lintas hasil harian Jalan Kertosono-Papar, Papar Kediri diolah menjadi data lalu lintas harian dan diperkirakan menjadi beban bagi jalan tol yang direncanakan. Untuk memperoleh laju pertumbuhan lalu lintas, digunakan data PDRB untuk melakukan perhitungan pertumbuhan lalu lintas kendaraan yang akan melewati jalan yang ditinjau sesuai dengan umur rencana jalan yaitu 40 tahun.

1. PDRB atas dasar harga konstan (ADHK) menggambarkan pertumbuhan lalu lintas untuk kendaraan pribadi.

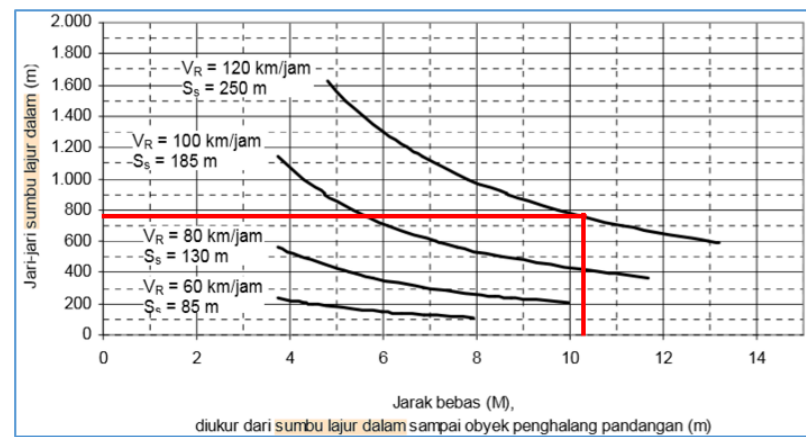

Gambar 3. Daerah Kebebasan Samping untuk Ss $<$ Lc. Tabel 7.

Rekapitulasi Faktor Pertumbuhan Kumulatif (R)

\begin{tabular}{|c|c|c|c|c|c|}
\hline $\begin{array}{c}\text { Jenis } \\
\text { Kendaraan } \\
\end{array}$ & & $\begin{array}{c}\text { Klasifikasi } \\
\text { Lama }\end{array}$ & $\begin{array}{c}\text { Kertosono- } \\
\text { Papar }\end{array}$ & $\begin{array}{l}\text { Papar- } \\
\text { Kediri }\end{array}$ & $\mathrm{R}$ \\
\hline Gol. I & $\begin{array}{c}\text { KR } \\
\text { KBM } \\
\text { BB }\end{array}$ & $2,3,4$ & 2411 & 3089 & 40,21 \\
\hline Gol. II & KBM & $5 a$ & 109 & 140 & 40,04 \\
\hline Gol. III & TB & $6 \mathrm{~b} 1.2$ & 464 & 525 & 40,20 \\
\hline Gol. IV & TB & $7 \mathrm{a} 3$ & 634 & 50 & 40,20 \\
\hline Gol. V & TB & $7 \mathrm{c} 1$ & 260 & 166 & 40,20 \\
\hline Gol. VI & SM & $7 \mathrm{c} 2.2$ & 281 & 604 & 40,20 \\
\hline \multicolumn{2}{|c|}{ JUMLAH } & & 4159 & 5075 & \\
\hline
\end{tabular}

Tabel 8.

Rekapitulasi Hasil Trip Assignment pada Tahun 2023

\begin{tabular}{|c|c|c|c|c|}
\hline $\begin{array}{c}\text { Jenis } \\
\text { Kendaraan }\end{array}$ & & $\begin{array}{c}\text { Klasifikasi } \\
\text { Lama }\end{array}$ & $\begin{array}{l}\text { Kertosono- } \\
\text { Papar }\end{array}$ & $\begin{array}{l}\text { Papar- } \\
\text { Kediri }\end{array}$ \\
\hline Gol. I & $\begin{array}{c}\text { KR } \\
\text { KBM } \\
\text { BB }\end{array}$ & $2,3,4$ & 884 & 1648 \\
\hline Gol. II & KBM & $5 a$ & 40 & 75 \\
\hline Gol. III & TB & $6 \mathrm{~b} 1.2$ & 170 & 280 \\
\hline Gol. IV & TB & $7 \mathrm{a} 3$ & 232 & 294 \\
\hline Gol. V & TB & $7 \mathrm{c} 1$ & 95 & 89 \\
\hline $\begin{array}{l}\text { Gol. VI } \\
\text { JUM }\end{array}$ & SM & $7 \mathrm{c} 2.2$ & $\begin{array}{c}103 \\
1525\end{array}$ & $\begin{array}{c}322 \\
2707\end{array}$ \\
\hline
\end{tabular}

2. PDRB per-kapita atas dasar harga konstan (ADHK) menggambarkan pertumbuhan lalu lintas untuk truk.

3. Data pertumbuhan penduduk menggambarkan pertumbuhan lalu lintas untuk bus dan angkutan umum.

\section{B. Data Sekunder Lalu Lintas}

Data lalu lintas didapatkan dari studi terdahulu dengan judul "Perancangan Trase Pembangunan Jalan Tol Kertosono-Kediri Ditinjau dari Kelayakan Ekonomi dan Finansial" [14] Oleh Dea Adlina Tiara Wibowo yang dibimbing oleh Ir. Hera Widyastuti, MT, Ph.D.

\section{Data Tanah $(C B R)$}

Dikarenakan data CBR tidak didapatkan maka di asusmsi CBR tanah efektif yaitu $6 \%$ dengan tanah urukan sebesar 30 $\mathrm{cm}$.

\section{PENENTUAN TRASE}

Perancangan trase menggunakan trase yang sudah dianalisa dari studi sebelumnya dengan judul "Perancangan Trase Pembangunan Jalan Tol Kertosono-Kediri Ditinjau dari Kelayakan Ekonomi dan Finansial" [4]. Sehingga didapatkan trase rencana Jalan Tol Kertosono-Kediri sebagaimana ditunjukkan pada Gambar 2.

Dalam merencanakan trase Jalan Tol Kertosono-Kediri, ada beberapa faktor yang menjadi pertimbangan yaitu: 
Tabel 9.

Rekapitulasi JKSNK Segmen Kertosono-Papar

\begin{tabular}{ccccc}
\hline $\begin{array}{c}\text { Klasifikasi } \\
\text { Lama }\end{array}$ & $\begin{array}{c}\text { LHR } \\
2023\end{array}$ & $\begin{array}{c}\text { Jumlah } \\
\text { Sumbu }\end{array}$ & $\begin{array}{c}\text { JKSNH } \\
(' 23)\end{array}$ & $\begin{array}{c}\text { JSKNK } \\
\text { ('23-'63) }\end{array}$ \\
\hline $2,3,4$ & 884 & - & - & - \\
$5 \mathrm{a}$ & 40 & 2 & 80 & 466.897 \\
$6 \mathrm{~b} 1.2$ & 170 & 2 & 340 & 1.995 .880 \\
$7 \mathrm{a} 3$ & 232 & 3 & 697 & 4.090 .959 \\
$7 \mathrm{c} 1$ & 95 & 4 & 382 & 2.241 .201 \\
7c2.2 & 103 & 5 & 514 & 3.018 .969 \\
TOTAL & & & 2.013 & 11.813 .907 \\
\hline \hline
\end{tabular}

Keterangan:

JKSNH : Jumlah kelompok sumbu niaga harian

JKSNK : Jumlah kelompok sumbu niaga kumulatif

Tabel 10.

Rekapitulasi JKSNK Segmen Papar-Kediri

\begin{tabular}{|c|c|c|c|c|}
\hline Klasifikasi & LHR & Jumlah & JKSNH & JSKNK \\
\hline Lama & 2023 & Sumbu & ('23) & ('23-'63) \\
\hline $2,3,4$ & 1648 & - & - & - \\
\hline $5 \mathrm{a}$ & 75 & 2 & 149 & 873.025 \\
\hline $6 \mathrm{~b} 1.2$ & 280 & 2 & 560 & 3.287 .161 \\
\hline $7 \mathrm{a} 3$ & 294 & 3 & 881 & 5.168 .204 \\
\hline $7 \mathrm{c} 1$ & 89 & 4 & 355 & 2.083 .653 \\
\hline $7 \mathrm{c} 2.2$ & 322 & 5 & 1.610 & 9.450 .855 \\
\hline TOTAL & & & 3.556 & 20.862 .897 \\
\hline
\end{tabular}

- Jumlah kelompok sumbu niaga kumulatif (JKSNK =

466.897) untuk segmen Kertosono-Papar Kendaraan

golongan 5a

- Faktor ditribusi arah $(\mathrm{DD}=0,5)$

- Faktor distribusi lajur $(\mathrm{DL}=80 \%)$

1. Faktor biaya, meliputi panjang trase, struktur jembatan, pembebasan sawah, pembebasan perkebunan, dan pembebasan pemukiman.

2. Faktor geometrik jalan, meliputi jumlah tikungan, dan kelandaian rata-rata jalan.

3. Faktor kepadatan penduduk, meliputi pertumbuhan penduduk rata-rata.

\section{PERANCANGAN GEOMETRIK}

\section{A. Kriteria Desain Perancangan Jalan Tol}

Perancangan geometrik jalan berdasarkan "Geometri Jalan Bebas Hambatan untuk Jalan Tol, Departemen Pekerjaan Umum Direktorat Jenderal Bina Marga tahun 2009"

Data yang ditentukan adalah sebagai berikut :

Nama jalan : Jalan Tol Kertosono-Kediri

Klasifikasi jalan : Jalan Bebas Hambatan

Tipe jalan : Empat lajur, dua arah, terbagi (4/2 D)

Lebar jalan $\quad: 2 \times 7,2 \mathrm{~m}$

Lebar bahu luar $\quad: 3,5 \mathrm{~m}$

Lebar bahu dalam $: 1,5 \mathrm{~m}$

Kecepatan rencana : $120 \mathrm{~km} / \mathrm{jam}$

Kelandaian maksimum : $3 \%$

\section{B. Perancangan Alinemen Horizontal}

Perencanaan alinemen horisontal ruas Jalan Tol Kertosono-Kediri menggunakan tikungan tipe Spiral-CircleSpiral (S-C-S). Pada Jalan Tol Kertosono-Kediri didapatkan jenis tikungan dengan jumlah PI 11 buah tikungan SpiralCircle-Spiral (SCS) yang dapat dilihat pada Tabel 1.

Stasioning Titik Parameter

Setelah menghitung parameter lengkung horizontal, maka selanjutnya adalah menentukan stasioning titik parameter lengkung horizontal yang dapat dilihat pada Tabel 2 .

\section{Perancangan Alinemen Vertikal}

Perancangan alinemen vertikal meliputi alinemen vertikal cekung dan cembung. Dalam menentukan panjang lengkung
Tabel 11.

Data Curah Hujan Stasiun Gading Parang

\begin{tabular}{ccc} 
Tahun & Waktu Kejadian & Rmaks $(\mathrm{mm})$ \\
2001 & 12-Maret & 141 \\
2002 & 9-Januari & 90 \\
2003 & 29-Januari & 100 \\
2004 & 12-Maret & 102 \\
2005 & 17-Desember & 114 \\
2006 & 24-April & 70 \\
2007 & 19-Mei & 110 \\
2008 & 5-Februari & 73 \\
2009 & 25-Maret & 60 \\
2010 & 20-Januari & 118 \\
2011 & 30-Januari & 85 \\
2012 & 26-Februari & 71 \\
2013 & 17-Juni & 118 \\
2014 & 23-Februari & 100 \\
\hline
\end{tabular}

Tabel 12.

Data Curah Hujan Stasiun Gading Parang

\begin{tabular}{ccc}
\hline \hline $\begin{array}{c}\text { Tipe } \\
\text { Saluran }\end{array}$ & B $(\mathrm{mm})$ & $\begin{array}{c}\mathrm{H} \\
(\mathrm{mm})\end{array}$ \\
\hline TIPE 1 & 200 & 300 \\
TIPE 2 & 250 & 400 \\
TIPE 3 & 300 & 400 \\
TIPE 4 & 350 & 500 \\
TIPE 5 & 450 & 500 \\
TIPE 6 & 550 & 600 \\
\hline
\end{tabular}

vertikal ini hanya menggunakan jarak pandang henti (Ss) karena jalan direncanakan dua arah (4/2D). Pada Jalan Tol Kertosono-Kediri didapatkan lengkung vertikal dengan jumlah PV 15 buah yang dapat dilihat pada Tabel 3 .

Stasioning Titik Parameter

Setelah menghitung parameter lengkung vertikal, maka selanjutnya adalah menentukan stasioning titik parameter lengkung vertikal yang dapat dilihat pada Tabel 4.

\section{Perhitungan Daerah Kebebasan Samping}

Daerah kebebasan samping ini perlu dihitung di setiap tikungan agar kita dapat memastikan lereng/daerah samping jalan tidak akan menghalangi pandangan pengemudi. Dasar perencanaan untuk hitungan ini adalah jari-jari lengkung dan panjang lengkung total yang didapatkan dari hasil perhitungan alinemen horisontal sebelumnya.

Berikut ini adalah contoh perhitungan untuk PI 1:

Data yang dibutuhkan:

$\mathrm{V}_{\mathrm{D}} \quad=120 \mathrm{~km} / \mathrm{jam}$

$\mathrm{R} \quad=750 \mathrm{~m}$

$\mathrm{S}_{\mathrm{S}} \quad=250 \mathrm{~m}$

$\mathrm{Lc} \quad=268,97 \mathrm{~m}$

$\mathrm{L}_{1}$ jalur $=7,2 \mathrm{~m}$

Jari-jari sumbu dalam:

$\mathrm{R}^{\prime}=\mathrm{R}-\left(0,5 \times \mathrm{L}_{1}\right.$ jalur $)=750-(0,5 \times 7,2)=746,40 \mathrm{~m}$

Karena nilai $\mathrm{S}_{\mathrm{S}}<\mathrm{Lc}$, maka rumus kebebasan samping di tikungan yang digunakan adalah :

$\mathrm{M}=\mathrm{R}^{\prime}\left(1-\cos \left(\frac{90 . S_{S}}{\pi R}\right)\right)=746,40\left(1-\cos \left(\frac{90.250}{\pi .746,40}\right)\right)=10,4 \mathrm{~m}$

Maka kebebasan samping yang diperlukan pada titik tikungan PI-1 sebesar 10,4 meter dari jari-jari sumbu lajur dalam.

Berdasarkan Gambar 3 untuk $\mathrm{S}_{\mathrm{S}}<\mathrm{L}_{\mathrm{C}}$, dengan nilai kecepatan desain $\left(\mathrm{V}_{\mathrm{D}}\right) 120 \mathrm{~km} / \mathrm{jam}$ dan jarak pandang henti $\left(\mathrm{S}_{\mathrm{S}}\right)$ sebesar $250 \mathrm{~m}$. Didapatkan nilai jarak kebebasan samping sebesar $10,4 \mathrm{~m}$. Untuk rekapitulasi pelebaran tikungan dapat dilihat pada Tabel 5.

\section{E. Pelebaran pada Tikungan}

Pada bagian terakhir perhitungan alinemen horisontal adalah menghitung pelebaran pada jalan yang bertujuan 
Tabel 12.

Data Curah Hujan Stasiun Gading Parang

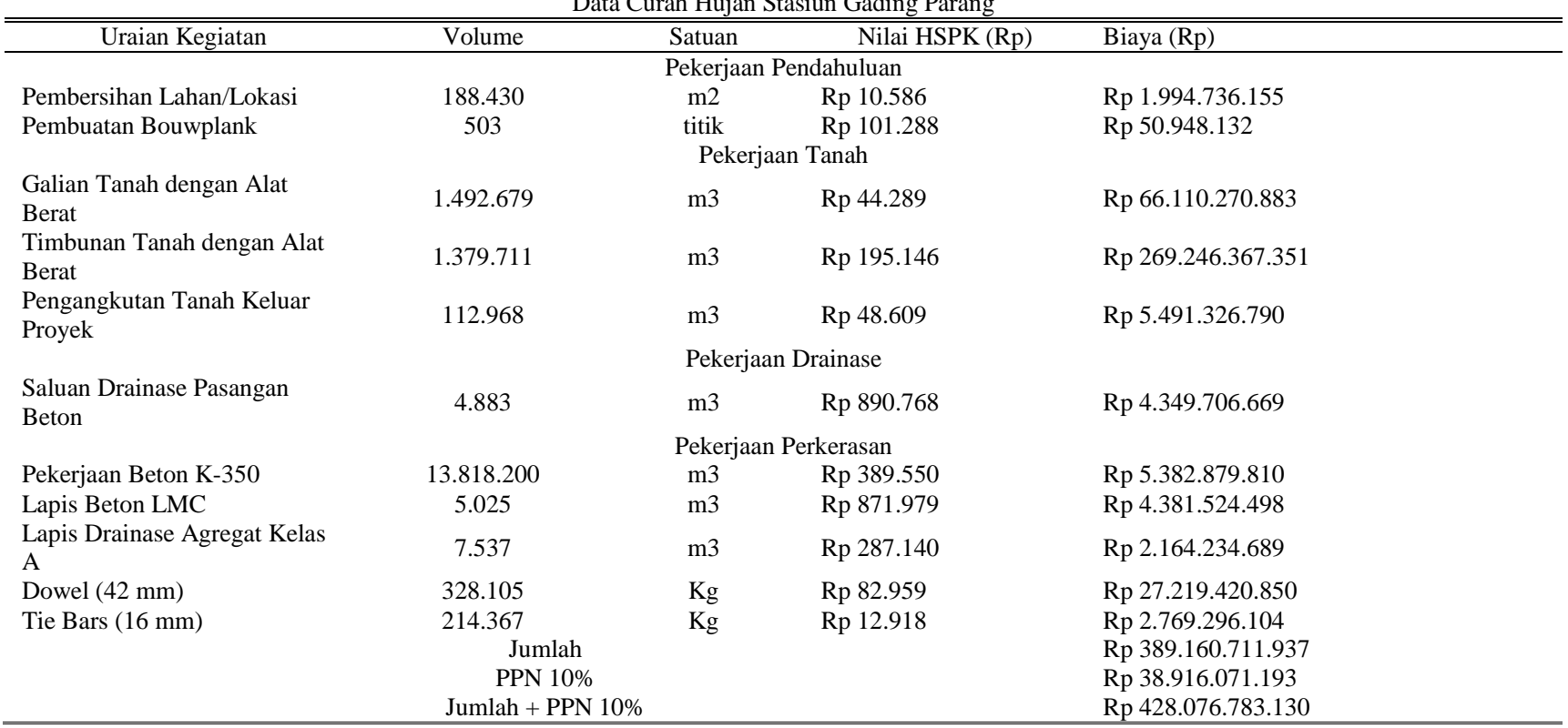

untuk mempertahankan kondisi pelayanan operasional lalu lintas di bagian tikungan.

Dikarenakan pelebaran untuk semua tikungan didapatkan sebesar 0,40 m dimana kurang dari 0,60 m, maka pelebaran tikungan dapat diabaikan.

\section{PERANCANGAN PERKERASAN JALAN}

\section{A. Pengolahan Data Lalu Lintas}

Direncanakan umur rencana jalan 40 tahun, Jalan Tol Kertosono-Kediri akan mulai beroperasi paada tahun 2023 dan akhir umur rencana 2063.

Data lalu lintas yang dipakai adalah di tahun 2016 yang didapat dari studi terdahulu dengan judul "Perancangan Trase Pembangunan Jalan Tol Kertosono-Kediri Ditinjau dari Kelayakan Ekonomi dan Finansial" [4]. Data lalu lintas kemudian di kalikan dengan faktor pertumbuhan lalu lintas pertahun sesuai dengan klasifikasi kendaraan.

\section{B. Pengolahan Data CBR}

Perancangan daya dukung tanah dasar bersasarkan Manual Desain Perkerasan Jalan diasumsikan tanah dasar mempunyai nilai CBR efektif yaitu $6 \%$ dengan tebal pondasi bawah minimal $300 \mathrm{~mm}$.

\section{Perancangan Tebal Pelat}

Untuk merencanakan tebal pelat maka melihat perhitungan presentase kendaraan tiap sumbu menurut klasifikasi Bina Marga dan memperhatikan umur rencana.

Faktor pertumbuhan lalu lintas (R) (Tabel 7)

Trip assignment

Analisis trip assignment digunakan untuk mengetahui dan memprediksi jumlah kendaraan yang akan berpindah dari jalan eksisting menuju ke Jalan Tol Kertosono-Kediri pada saat Jalan Toltersebut dibuka pada tahun 2023.

Hasil analisis trip assignment menggunakan data dari studi terdahulu dengan judul "Perencanaan Trase Pembangunan Jalan Tol Kertosono-Kediri Ditinjau dari Kelayakan Ekonomi dan Finansial" [4]. (Tabel 8,9 dan 10)

Repetisi yang terjadi (CESAL):

CESAL $=365 \times \mathrm{R} \times \mathrm{JKSNK} \times \mathrm{DD} \times \mathrm{DL}$

$$
=11.813 .907 \text { buah }=11,8 \mathrm{E}+6 \text { buah }
$$

Dari repetisi yang terjadi dihubungkan tebal perkerasan dengan beban sumbu kendaraan rencana didapat:

Perkerasan badan jalan sebagai berikut.

$\begin{array}{lll}\text { - } & \text { Tebal pelat beton } & =285 \mathrm{~mm} \\ \text { - } & \text { Lapis fondasi LMC } & =100 \mathrm{~mm} \\ \text { - } & \text { Lapis drainase } & =150 \mathrm{~mm}\end{array}$

Perkerasan bahu jalan sebagai berikut.

$$
\begin{array}{lll}
\text { - } & \text { Tebal pelat beton } & =265 \mathrm{~mm} \\
\text { - } & \text { Lapis fondasi LMC } & =100 \mathrm{~mm} \\
\text { - } & \text { Lapis drainase } & =150 \mathrm{~mm}
\end{array}
$$

\section{PERANCANGAN SALURAN DRAINASE}

\section{A. Pengolahan Data Curah Hujan}

Direncanakan umur rencana saluran drainase selama 20 tahun. Data curah hujan yang dipakai adalah data curah hujan harian maksimum selama 14 tahun yang didapatkan dari Dinas Pengairan, Pertambangan, dan Energi Kabupaten Kediri. Data Curah Hujan Stasiun Gading Parang dapat dilihat pada Tabel 11.

\section{B. Analisa Hidrologi}

Direncanakan umur rencana saluran drainase selama 20 tahun. Berikut ini adalah langkah langkah dalam menghitung analisa hidrologi.

Dibawah ini adalah contoh perhitungan pada STA 0+000 sampai STA 0+420 debit aliran dengan analisis hidrologi pada jalan rencana sesuai dengan umur rencana :

1. Menentukan to pakai

$$
\begin{aligned}
& \mathrm{t}_{0 \text { jalan }}=\mathrm{t}_{0 \text { bahu dalam }}+\mathrm{t}_{0 \text { badan jalan }}+\mathrm{t}_{0 \text { bahu luar }} \\
& =0,0087+0,0199+0,0141=0,0426 \mathrm{jam} \\
& \mathrm{t}_{0 \text { lereng }}=0,060 \mathrm{jam} \\
& \mathrm{t}_{0 \text { jalan }}<\mathrm{t}_{0 \text { lereng }} \\
& 0,0426 \text { jam }<0,060 \text { jam } \\
& \mathrm{t}_{0} \text { pakai }=\mathrm{t}_{0 \text { lereng }}=0,060 \text { jam }
\end{aligned}
$$

2. Menghitung waktu pengaliran di saluran ( $t$ f)

$$
\mathrm{t}_{\mathrm{f}}=\frac{\text { Lsaluran }}{60 \times \mathrm{V}}=\frac{420}{60 \times 0,5}=0,233 \mathrm{jam}
$$

3. Menghitung intensitas hujan (I) 


$$
\begin{aligned}
& \mathrm{I}=\frac{R 24}{24} \times\left(\frac{24}{t c}\right)^{\frac{2}{3}}=\frac{152,552}{24} \times\left(\frac{24}{0,293}\right)^{\frac{2}{3}}=119,787 \mathrm{~mm} / \mathrm{jam} \\
& \text { 4. Menghitung koefisien pengaliran ( } \mathrm{Cgab} \text { ) } \\
& \mathrm{C}_{\text {gabungan }}= \\
& \frac{C_{b . d l m} \cdot A_{b . d l m}+C_{b d n j l n} \cdot A_{b d n ~ j l n}+C_{b . l u a r} \cdot A_{b . l u a r}+C_{\text {lrng. }} A_{\text {lrng.fk }}}{A_{\text {b.dalam }}+A_{\text {badan jalan }}+A_{\text {b.luar }}+A_{\text {lereng }}} \mathrm{C}_{\mathrm{ga}} \\
& \text { bungan }= \\
& 0,80 \times 0,0006+0,80 \times 0,0030+0,80 \times 0,0015+0,80 \times 0,0026 \times 0,3 \\
& \mathrm{C}_{\text {gabungan }}=0,6094 \\
& 0,0006+0,0030+0,0015+0,0026 \\
& =0,278 \times 0,6094 \times 119,787 \times 0,0078 \\
& =0,158 \mathrm{~m}^{3}
\end{aligned}
$$

\section{Analisa Hidrolika}

Dalam analisa hidrolika berikut bertujuan untuk mengetahui kemampuan penampang dalam menampung debit rencana sesuai dengan umur rencana jalan.

Dibawah ini adalah contoh perhitungan debit aliran dengan analisis hidrolika pada jalan rencana sesuai dengan umur rencana :

STA 0 sampai dengan STA 0+1800.

1. Perhitungan dimensi penampang saluran $(A)$

$$
\begin{array}{ll}
\mathrm{B}_{\text {rencana }} & =0,27 \mathrm{~m} \\
\mathrm{H}_{\text {rencana }} & =0,13 \mathrm{~m} \\
\mathrm{Z} & =1,5 \\
\mathrm{~A}_{\text {saluran }} & =(\mathrm{b}+\mathrm{m} \cdot \mathrm{h}) \cdot \mathrm{h}=(0,27+1 \cdot 0,13) \cdot 0,13=0,333 \mathrm{~m}^{2}
\end{array}
$$

Tinggi jagaan $(\mathrm{w})=\sqrt{0,5 \times \text { hrencana }}$

$$
=\sqrt{0,5 \times 0,13}=0,26 \mathrm{~m}
$$

Keliling basah $(\mathrm{P})=b+2 h \cdot \sqrt{z^{2}+1}$

$$
\begin{aligned}
& =0,27+2 \cdot 0,13 \cdot \sqrt{1,5^{2}+1} \\
& =1,675
\end{aligned}
$$

Jari-jari hidrolis $(\mathrm{R})=\frac{A}{P}=\frac{0,333}{1,675}=0,199 \mathrm{~m}$

$$
\begin{aligned}
\mathrm{I}_{\text {rencana }} & =0,0005 \\
\mathrm{~V}_{\text {hidrolika }} & =\frac{1}{n} \times R^{\frac{2}{3}} \times I^{\frac{1}{2}}=\frac{1}{0,016} \times 0,199^{\frac{2}{3}} \times 0,0033^{\frac{1}{2}} \\
& =1,121
\end{aligned}
$$

2. Kontrol kecepatan aliran (v)

$$
\mathrm{V}_{\text {hidrolika }}<\mathrm{V}_{\mathrm{ijin}}
$$

$0,476 \mathrm{~m} /$ detik $<1,50 \mathrm{~m} / \operatorname{detik}(\mathbf{O K})$

3. Kontrol debit $(\Delta Q)$

$$
\begin{aligned}
& \text { Qhidrolika }=V_{\text {hidrolika }} \times A_{\text {hidrolika }} \\
& =0,576 \times 0,333=0,158 \mathrm{~m}^{3} / \text { detik } \\
& \text { Qhidrologi }<\text { Qhidrolika } \\
& 0,158 \mathrm{~m}^{3} / \text { detik }<0,158 \mathrm{~m}^{3} / \text { detik } \\
& \mathrm{Q}_{\text {hidrolika }} \text { - Qhidrologi }=0,158-0,158 \mathrm{~m}^{3} / \text { detik } \\
& =0 \mathrm{~m}^{3} / \text { detik }<4 \%(\mathbf{O K})
\end{aligned}
$$

Dari perhitungan kontrol debit yang telah dilakukan, didapatkan tipe saluran drainase sebanyak 6 tipe berbentuk trapesium.

\section{RENCANA ANGGARAN BIAYA (RAB)}

\section{A. Analisa Harga Satuan Pekerjaan}

Pada subbab ini akan di breakdown analisa harga satuan pekerjaan. HSPK yang digunakan merupakan HSPK Surabaya Tahun 2019 dengan melakukan penyesuaian terhadap HSPK Kota Kediri. Penyesuaian terhadap HSPK Kota Kediri menggunakan faktor 97,85 yang didapatkan dari website Badan Pusat Statistik Nasional.

\section{B. Perhitungan Volume Pekerjaan}

Perhitungan volume pekerjaan tidak menghitung tentang pembebasan lahan, bangunan pelengkap jalan, rambu dan marka jalan, dan penerangan jalan. Perhitungan volume pekerjaan meliputi:

1) Pekerjaan pendahuluan

a. Pembersihan lahan/lokasi

Pembersihan areal pekerjaan sesuai dengan volume yang ada dengan cara membersihkan tanaman semak belukar yang ada disekitar lokasi agar dalam pelaksanaan pekerjaan nantinya tidak ada kendala.

b. Pembuatan bouwplank

Bouwplank harus dibuat tegak lurus. Patok dan bouwplank harus dibuat kokoh, tidak mudah rusak dan tidak bergerak serta harus dijaga agar tidak rusak/hilang selama pelaksanaan pekerjaan dengan jarak antar patok 50 meter disesuaikan dengan perpotongan STA. Dalam perancangan Jalan Tol Kertosono-Kediri ini memerlukan 503 titik pemasangan bouwplank.

2) Pekerjaan tanah

a. Galian tanah dengan alat berat

Galian tanah adalah penggalian tanah dengan menggunakan alat berat misalnya excavator (tergantung kebutuhan). Luas dari galian didapatkan dari program bantu AutoCad Civil3d yang dinilai lebih akurat. Didapatkan cut volume sebesar $1.492 .679 \mathrm{~m}^{3}$.

b. Timbunan tanah dengan alat berat

Luas dari timbunan didapatkan dari program bantu AutoCad Civil3d yang dinilai lebih akurat. Didapatkan fill volume sebesar $1.379 .711 \mathrm{~m}^{3}$.

c. Pengangkutan tanah keluar proyek

Tanah yang sudah digali selanjutnya akan diangkut keluar untuk menuju lokasi penimbunan. Didapatkan volume pengangkutan tanah $112.968 \mathrm{~m}^{3}$.

\section{3) Pekerjaan drainase}

Volume dari pekerjaan drainase didapatkan secara otomatis berdasarkan volume galian dan timbunan dengan bantuan program bantu AutoCad Civil 3D.

4) Pekerjaan perkerasan jalan

Didapatkan volume sebagai berikut:

a. Volume lapisan

$$
\begin{array}{lr}
\text { Rigid pavement } & =13.818 \mathrm{~m}^{3} \\
\text { Lapis beton LMC } & =5.025 \mathrm{~m}^{3} \\
\text { Lapis drainase } & =7.537 \mathrm{~m}^{3}
\end{array}
$$

b. Kebutuhan batang tie bars $=214.367 \mathrm{~kg}$

c. Kebutuhan dowel $\quad=328.105 \mathrm{~kg}$

\section{Rencana Anggaran Biaya}

Pada perancangan Jalan Tol Kertosono-Kediri, didapatkan RAB sebesar Rp 428.076.783.131. (Tabel 12)

\section{KESIMPULAN}

Berdasarkan perancangan yang telah dibahas pada bab-bab sebelumnya, maka didapat kesimpulan sebagai berikut:

1. Geometrik Jalan

Pada Jalan Tol Kertosono-Kediri didapatkan lengkung horizontal dengan jumlah 11 buah tikungan SpiralCircleSpiral (SCS) dan lengkung vertikal sebanyak 15 buah.

2. Perkerasan Jalan

Perkerasan kaku di desain menggunakan Rigid Pavement yang didesain menggunakan Manual Desain Perkerasan (MDP) Tahun 2017 meliputi perkerasan 
pada badan jalan dan bahu jalan. Berdasarkan perhitungan sebelumnya didapatkan tebal perkerasan sebagai berikut :

Perkerasan untuk badan jalan, sebagai berikut:

Tebal pelat beton $\quad=285 \mathrm{~mm}$

Lapis Fondasi LMC $=100 \mathrm{~mm}$

Lapis Drainase $\quad=150 \mathrm{~mm}$

Perkerasan untuk bahu jalan, sebagai berikut:

Tebal pelat beton $=265 \mathrm{~mm}$

Lapis Fondasi LMC $=100 \mathrm{~mm}$

Lapis Drainase $\quad=150 \mathrm{~mm}$

3. Saluran Drainase

Saluran drainase dirancang menggunakan saluran tipe u-ditch berbentuk trapesium. Didapatkan 6 tipe saluran sebagai berikut:
Tipe 1
$\mathrm{B}=200 \mathrm{~mm}$
$\mathrm{H}=300 \mathrm{~mm}$
Tipe 2
$\mathrm{B}=250 \mathrm{~mm}$
$\mathrm{H}=400 \mathrm{~mm}$
Tipe 3
$\mathrm{B}=300 \mathrm{~mm}$
$\mathrm{H}=400 \mathrm{~mm}$
Tipe 4
$\mathrm{B}=350 \mathrm{~mm}$
$\mathrm{H}=500 \mathrm{~mm}$
Tipe 5
$\mathrm{B}=450 \mathrm{~mm}$
$\mathrm{H}=500 \mathrm{~mm}$

Tipe $6 \quad \mathrm{~B}=550 \mathrm{~mm} \quad \mathrm{H}=600 \mathrm{~mm}$

4. Anggaran Biaya Material

Berdasarkan perhitungan volume setiap pekerjaan dan analisa harga satuan pokok kegiatan diperoleh total biaya konstruksi sebesar Rp. 428.076.783.100,- (Empat Ratus Dua Puluh Delapan Miliar Tujuh Puluh Enam Juta Tujuh Ratus Delapan Puluh Tiga Seratus Rupiah).

\section{DAFTAR PUSTAKA}

[1] Pemerintahan Republik Indonesia, "Undang-Undang Republik Indonesia Nomor 38 Tahun 2004 Tentang Jalan," Jakarta, 2004

[2] Badan Pusat Statistik, "Provinsi Jawa Timur Dalam Angka 2017," Surabaya, 2017.

[3] Pemerintah Republik Indonesia, "Peraturan Pemerintah Nomor 13 Tahun 2017 tentang Rencana Tata Ruang Wilayah Nasional," Jakarta.

[4] D. Wibowo, "Perencanaan Trase Pada Pembangunan Jalan Tol Kertosono-Kediri Ditinjau Dari Kelayakan Ekonomi dan Finansial," Surabaya, 2019. 